\title{
Letter to Editor: Mortality Trends of Pilgrims in Hajj: An Implication for Establishment of Surveillance System
}

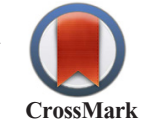

Citation: Ghodsi H, Khorasani-Zavareh D, Khodadadizadeh A, Yusefnezhad S. Mortality Trends of Pilgrims in Hajj: An Implication for Establishment of Surveillance System. Health in Emergencies and Disasters Quarterly. 2017; 2(4):163-164.

\section{Introduction}

Hajj is one of the most important religious ceremonies of Muslims that is held in Saudi Arabia every year. However, trauma is the most important factor of mortality in this ceremony.

\section{Materials and Methods}

Document reviews including Saudi Arabia Ministry of Health reports, articles and news about injuries in Hajj were used for data collection. Most of the casualties during Hajj were observed in 1990 and 2015. The highest number of casualties of Hajj pilgrims occurred on $24^{\text {th }}$ of September 2015 due to overcrowding. Regarding the occurrence of such tragic events, it should be noted that there is a lack of official and accurate data to provide the demographics of the deceased, main cause of event occurrence, and the exact number of injured and dead. Procurement of this information can help the authorities in preventing the occurrence of such events.

In addition, it is also necessary to introduce appropriate intervention in the surveillance system. Different sources have defined mass gathering differently. Some sources have defined mass gathering as the spontaneous or previously planned presence of more than 1000 people, whereas other sources have defined it as the presence of more than 25000 people in a short period of time at a specified place for a special purpose [1-4]. Various factors, such as weather, characteristics of participants, number of those present at the ceremony, kind of ceremony, and time of holding, can affect population health at mass gatherings. These factors can cause a wide range of injuries including minor injuries, trauma, musculoskeletal injuries, infectious diseases, and mortality $[5,6]$.

Hajj is one of the most important religious ceremonies of Muslims that is held in Saudi Arabia every year, and millions of people worldwide participate in it [2]. The Hajj ceremony is most attended by people who are old, and accordingly may be sick or disabled. Hence, the issues associated with this ceremony are different from other mass gatherings. [7]. For data collection, we reviewed the existing documents on all the events that occurred during the past Hajj ceremonies from June 2016 up to September 2016. All these documents were obtained from sources like Google scholar, Web of science, Scopus and PubMed.

Table 1. Mortality trends in Hajj 1990-2015 caused by stampede of pilgrims

\begin{tabular}{ccc}
\hline Year & Number of Deaths \\
\hline 1990 & 1426 \\
\hline 1998 & 270 & 119 \\
\hline 2001 & 35 & 14 \\
\hline 2003 & 251 \\
\hline 2004 & 380 \\
\hline 2006 & 4173 \\
\hline
\end{tabular}

Emergencies and |D]isasters [O]uarterly 
In the Hajj ceremony, trauma is the most important factor associated with mortality. Stampedes, which mainly occur during Rami Jamarat (stoning of the devil) in tenth day of Zihajja due to the short duration of the ceremony, are the scariest cause of mortality in pilgrims [8]. According to the World Health Organization about the necessity of using epidemiological data before any intervention, it is necessary that pattern of deceased mortality taken as the first action [9].

As per the reviewed documents, most of the casualties during Hajj occurred in 1990 and 2015 (Table 1). On the 2nd of January 1990, during the departure of pilgrims to the Jamarat region via a tunnel of width 10 meter, the tunnel ventilation system shut down, resulting in a stampede in which 1426 pilgrims died due to the influx of people to the exits [5].

The worst event in the history of Hajj occurred on the $24^{\text {th }}$ of September 2015, when 4173 pilgrims were killed due to overcrowding at the ceremony [10]. The high number of deaths was mainly due to overcrowding, high aggregation on the way, closed exit to the Jamarat, high temperature, thirst and lack of drinking water, disregard of guidance by pilgrims, and a delay in relief [11]. Regarding the occurrence of such tragic events, it should be noted that there is a lack of official and accurate data to provide the demographics of the deceased, main cause of event occurrence, and the exact number of injured and dead. Procurement of these information can help the authorities in preventing the occurrence of such events.

With the increasing number of participants in Hajj every year and despite the actions taken to improve the situation, tragic events and deaths of the pilgrims do occur. Hence, it is necessary to plan appropriate interventions for the prevention of such events. In addition, it is necessary to introduce appropriate intervention in the surveillance system. Accordingly, the surveillance system should have the following goals: 1 . Monitoring of the trends of mortality in Hajj; 2. Determination of the cause of mortality in Hajj; 3. Identification of the age and sex groups at risk; 4. Contribution to the design of interventions; and 5. Evaluation of intervention programs.

Hasan Ghodsi ${ }^{1,2}$, Davoud Khorasani-Zavareh1 $1^{1,3,4^{*}}$, Ali Khodadadizadeh $^{1}$, Sadegh Yusefnezhad ${ }^{1}$

1. Department of Health in Disasters and Emergencies, School of Health, Safety and Environment, Shahid Beheshti University of Medical Sciences, Tehran, Iran.

2. Department of Nursing and Midwifery, School of Medical Sciences, Neyshabur University of Medical Sciences, Neyshabur, Iran.
3. Safety Promotion and Injury Prevention Research Center, Shahid Beheshti University of Medical Sciences, Tehran, Iran.

4. Department of Clinical Science and Education, Karolinska Institutet, Stockholm, Sweden.

\section{* Corresponding Author:}

Davoud Khorasani-Zavareh, $P h D$

Address: Department of Health in Disasters and Emergencies, School of Health, Safety and Environment, Shahid Beheshti University of Medical Sciences, Tehran, Iran.

E-mail: davoud.khorasani@gmail.com

\section{References}

[1] Enock KE, Jacobs J. The Olympic and paralympic games 2012: Literature review of the logistical planning and operational challenges for public health. Public Health. 2008; 122(11):1229-38. doi: 10.1016/j.puhe.2008.04.016

[2] Lombardo JS, Sniegoski CA, Loschen WA, Westercamp M, Wade M, Dearth S, et al. Public health surveillance for mass gatherings. Johns Hopkins APL Technical Digest. 2008; 27(4):347-55.

[3] Milsten AM, Maguire BJ, Bissell RA, Seaman KG. Massgathering medical care: A review of the literature. Prehospital and Disaster Medicine. 2002; 17(3):151-62. doi: 10.1017/ s1049023x00000388

[4] Global Alert and Response. Communicable disease alert and response for mass gatherings: Key considerations. Geneva: World Health Organization; 2008.

[5] Ahmed QA, Arabi YM, Memish ZA. Health risks at the Hajj. The Lancet. 2006; 367(9515):1008-15. doi: 10.1016/s01406736(06)68429-8

[6] Arbon P. Mass gathering medicine: A review of the evidence and future directions for research. Prehospital and Disaster Medicine. 2007; 22(2):131-5. doi: 10.1017/s1049023x00004507

[7] Spinney L. At largest religious festival, some abandon elderly. National Geographic News. 2013 February 22.

[8] Helbing D, Farkas I, Vicsek T. Simulating dynamical features of escape panic. Nature. 2000; 407(6803):487-90. doi: $10.1038 / 35035023$

[9] Department of Information, Evidence and Research. WHO methods and data sources for country level causes of death 2000-2015. Geneva: World Health Organization, Department of Information, Evidence and Research; 2017.

[10] Saudi's Health Ministry. Mina disaster death toll hits 4173. Al-Alam. 2015 September 29.

[11] Wikipedia. 2015 Mina stampede [Internet]. 2016 [Updated 2016 May 13]. Available from: https:// en.wikipedia.org/w /index.php?title=2015_Mina_ stampede\&oldid $=720003644 . \% 20$ Accessed $\% 20 \mathrm{June} \% 20$ $17, \% 202016$ 